Ann. Zootech., 1983, 32 (3), 315-340

\title{
Digestion des protéines dans l'intestin grêle chez le porc \\ II - Composition en acides aminés des digesta : influence de la source de protéines d'un régime à base d'amidon de maïs purifié et variations postprandiales
}

\author{
Béatrice DARCY, J.P. LAPLACE et P.H. DUEE (*) \\ avec la collaboration technique de Régime CALmes, Georgette Fredou, \\ Janine Jung, Brigitte Mourot, Françoise Sene et Alfred Roger \\ I.N.R.A., Laboratoire de Physiologie de la Nutrition \\ Centre de Recherches Zootechniques, 78350 Jouy-en-Josas
}

\begin{abstract}
Résumé
La digestibilité iléale des acides aminés d'un régime à base d'amidon de maïs purifié associć à une farine de poisson ou à un gluten de blé a été précédemment rapportée. Le présent travail décrit pour ces mêmes régimes l'évolution postprandiale $(24 \mathrm{~h})$ de la composition en acides aminés des digesta recueillis par fistulation iléo-colique post-valvulaire. La composition des digesta est effectivement différente selon la nature des protéines alimentaires ingérées. Cette différence s'observe aussi bien sur des échantillons moyens de $24 \mathrm{~h}$ que pour chacune des collectes consécutives $(0-4 \mathrm{~h}, 4-6 \mathrm{~h}, 6-8 \mathrm{~h}, 8-14 \mathrm{~h}$ et 14-24 $\mathrm{h}$ après le repas). L'étude de la composition des digesta en acides aminés totaux et libres a été effectuée par analyse multidimensionnelle (analyse factorielle des correspondances). Cette méthodologie permet de comparer ces compositions à celles des protéines alimentaires, des digesta recueillis en régime protéiprive, et de diverses protéines d'origine endogène. De plus, elle permet de tenter d'estimer la part de différentes sources de protéines dans la composition des digesta ilćaux.
\end{abstract}

Au total, l'influence des protéines alimentaires s'avère importante même dans le cas d'une protéine hautement digestible comme le gluten. Cet effet, apparent dans les premières heures postprandiales, en régime gluten, apparaît plus tardivement mais persiste plus de $12 \mathrm{~h}$ après le repas en régime poisson. L'influence des protéines alimentaires à ce niveau semble correspondre à la présence de fractions protéiques particulières, résistantes à la digestion. Une telle étude de composition est nécessaire pour saisir les réalités physiologiques différentes sous-jacentes à des différences de digestibilité iléale.

\section{Introduction}

La très forte proportion d'azote d'origine bactérienne dans l'azote fécal, excédant généralement 50 p. 100 , entraîne une relative stabilité de la composition des fèces en

(*) Adresse actuelle : Centre de Recherches sur la Nutrition, C.N.R.S., 9, rue J.-Hetzel, 92190 Meudon-Bellevue. 
acides aminés (Mason, Just \& Bech-Andersen, 1976). Au niveau de l'ilcon terminal, l'influence de la nature des protéines du régime, partiellement masquée par les apports endogènes, reste controversée. Elle a été mise en évidence par HoLmEs et al. (1974), BURACZEWSKA et al. (1975) et WüNSCHE et al. (1979 a) et à l'inverse contestée par d'autres auteurs (ZeBrowsKa et al., 1976 ; Low, 1982 ; LeibHolz, 1982) qui observent une accumulation d'acides aminés d'origine endogène au niveau iléal, sous la forme de protéines non dégradées.

Ces résultats divergents peuvent toutefois découler d’une méthodologie non appropriée : en effet, la plupart des données sont fondées sur l'analyse d'un seul échantillon de contenu digestif portant sur une période de collecte de $24 \mathrm{~h}$. Une analyse sériée de l'évolution postprandiale de la composition en acides aminés des digesta semble constituer une approche plus judicieuse de ce problème. Ces variations de composition des digesta, recueillis après fistulation iléo-colique post-valvulaire, ont été appréhendées en appliquant une technique mathématique d'analyse multidimensionnelie.

Ce travail constitue le complément de l'étude de la digestibilité iléale de l'amidon et de lazote (Darcy, Laplace \& Villiers, 1981) et des acides aminés (Darcy, LAPLACE \& DuÉE, 1982) pour des régimes à base d'amidon de maïs purifié dont les protéines sont apportées soit par une farine de poisson, soit par un gluten de blé.

\section{Matériel et méthodes}

\section{A. Matériel expérimental}

Le protocole utilisé a été décrit en détail dans le précédent article (DARCY, LAPlace \& Dú́E, 1982). Trois porcs ont reçu successivement les deux régimes à 16 p. 100 de protéines brutes (farine de poisson ou gluten de blé) dont la composition en acides aminés (AA) a été précisée. Deux autres porcs ont reçu sans accoutumance préalable un régime protéiprive. La fistulation iléo-colique post-valvulaire a permis de collecter chez ces animaux la totalité des digesta écoulés $4,6,8,14$ et 24 h après un repas unique distribué à $9 \mathrm{~h}$ chaque jour. Le nombre d’épreuves réalisées au total est respectivement de 6, 5 et 9 pour les régimes «poisson», «gluten» et «protéiprive». Sur les échantillons représentatifs de ces collectes ont été dosés les AA totaux selon une méthodologie détaillée précédemment. Parallèlement, pour les régimes azotés, un second échantillon $(40 \mathrm{~g})$ a été prélevé lorsque la collecte s'est avérée suffisante. Après centrifugation $(2500 \mathrm{~g} ; 20 \mathrm{mn})$, on a déterminé la teneur en matière sèche et en azote total du surnageant. Une fraction aliquote $(2 \mathrm{ml})$ a été déprotéinisée par l'acide sulfosalicylique $(8 \mathrm{ml}$ de solution à $3 \mathrm{p}$. 100). Après agitation et centrifugation $(6500 \mathrm{~g}$; $20 \mathrm{mn}$ ), le dosage des AA libres a été effectué sur le surnageant dans les mêmes conditions analytiques que pour les AA totaux.

Les 17 AA déterminés sont désignés comme dans le précédent article par leurs abréviations conventionnelles. On utilisera également les abréviations suivantes : EAA : acides aminés indispensables (ou essentiels) et semi-indispensables, NAA : acides aminés non indispensables, $\Sigma$ AA : somme des $17 \mathrm{AA}$. 


\section{B. Analyse statistique des résultats}

Les différentes valeurs ont été comparées 2 à 2 , selon le régime. par un test de $\mathrm{t}$ de Student. De plus, une méthode mathématique d’analyse des données, lanalyse factorielle des correspondances (LebarT, MORINEAU \& TABART, 1977), a été utilisée pour comparer globalement la composition en AA des différents échantillons correspondant à un régime et à un temps de collecte (Guilloteau, Sauvant \& Patureau-Mirand, 1983). Les propriétés essentielles de ce type d'analyse sont les suivantes : (i) deux échantillons (observations expérimentales) ayant des compositions en AA voisines ont des projections proches sur les axes ou les plans sur lesquels ils sont bien représentés; (ii) la proximité des points de projection d'un AA individuel (variable) et d'un échantillon implique que ce dernier peut être caractérisé par sa teneur en l'AA considéré.

Par ailleurs, il est possible dintroduire dans lanalyse certains échantillons de référence en tant qu’individus «supplémentaires»ou «illustratifs». Ceux-ci, à l'inverse des individus "principaux» ou "actifs», n'interviennent pas dans la détermination des axes, mais sont projetés sur les plans définis par ces axes factoriels préalablement identifiés. La liste des échantillons de référence est fournie en annexe : il s'agit de la composition d'une part des protéines de l'aliment (farine de poisson ou gluten de blé) et dautre part de diverses sources dazote endogène ou bactérien. Les observations portant sur les AA libres ont également été introduites à titre d’individus supplémentaires.

Enfin, pour chacun des temps de collecte et chacun des régimes, nous avons tenté de déterminer, selon une méthode déjà utilisée par Guilloteau et al. (1980), les proportions de protéines alimentaires, endogènes ou bactériennes dans les digesta qui permettent d'expliquer leur composition moyenne en AA. Ceci est réalisé en calculant les compositions théoriques en AA de mélanges de ces protéines différant par leurs proportions de la façon suivante :

- en régime azoté :

composition estimée

des digesta $(17 \mathrm{AA})=\mathrm{a} \times \mathrm{A}+\mathrm{b} \times \mathrm{B}+\mathrm{c} \times \mathrm{C}+\mathrm{d} \times \mathrm{D}$

- en régime protéiprive :

composition estimée

des $\operatorname{digesta}(17 \mathrm{AA})=\mathrm{b} \times \mathrm{B}+\mathrm{c} \times \mathrm{C}+\mathrm{d} \times \mathrm{D}$

$a, b, c$ et d prennent toutes les valeurs comprises entre 0 et 1 , avec un pas de 0,1 , et sous la contrainte $a+b+c+d=1$ (régimes azotés) ou $b+c+d=1$ (régime protéiprive).

$\mathrm{A}=$ composition (17 AA) de l’aliment farine de poisson ou gluten de blé (Darcy, Laplace \& DuÉe, 1982).

$\mathrm{B}=$ composition (17 AA) de la sécrétion pancréatique de porc (CORRING \& JUNG, 1972)

$\mathrm{C}=$ composition $(17 \mathrm{AA}) \mathrm{du}$ mucus intestinal de porc

(Darcy \& Calmes, données non publiées).

$\mathrm{D}=$ composition (17 AA) des bactéries fécales de porc

(MASON, Just \& Bech-ANDERSEN, 1976). 
Les proportions retenues sont celles qui fournissent la composition théorique du mélange la plus proche de celle observée (distance du $\chi^{2}$ minimale).

\section{Résultats}

\section{A. Evolution des quantités collectées d'acides aminés totaux et essenticls}

Les données précédemment rapportées (DARCy, LAPlace \& DuéE, 1982) ont montré que les quantités d'AA collectées au cours d'un nycthémère sont beaucoup plus élevées dans le cas du régime poisson que dans celui du régime gluten. Cet effet lié à la source protéique se retrouve quelle que soit la fraction du nycthémère considéré (tabl. 1). La quantité globale collectée en 24 heures avec le régime protéiprive, est voisine de celle obtenue avec le régime gluten; toutefois les quantités recueillies durant les deux premières collectes $(0-4 \mathrm{~h}, 4-6 \mathrm{~h})$ sembient être moindres. Indépendamment de la source protéique, le flux maximal d'AA (quantités en $\mathrm{g} / \mathrm{h}$ pour chaque période de collecte) est obtenu durant les fractions de temps $4-6 \mathrm{~h}$ et 6-8 $\mathrm{h}$ (tabl. 1). Ceci est particulièrement net pour le régime poisson puisque pendant ce laps de temps de $4 \mathrm{~h}$ (17 p. 100 du nycthémère), 40 p. 100 des quantités d'AA sont recueillies. D'ailleurs, le premier tiers du nycthémère postprandial représente la période où plus de la moitié des quantités d'AA sont collectées dans le cas du régime poisson, contre 36 p. 100 dans le cas du régime gluten.

La fraction libre des AA dans les contenus digestifs reste relativement limitéc (7 à 16 p. 100 de la quantité totale d'AA), et peu dépendante du temps de prélèvement et de la source protéique. Ses variations sont done tributaires de l'évolution des quantités totales d'AA. Un léger enrichissement en AA libres est cependant à noter dans le premier tiers du nycthémère avec le régime gluten de blé.

La teneur en AA de la matière sèche des digesta (tabl. 2) est en régime poisson $(10,6$ à 16,5 p. 100) constamment supérieure à celle obtenue avec le régime gluten (7,0 à 9,7 p. 100). Dans le cas du régime protéiprive, la teneur en AA de la matière sèche apparaît également plus élevée $(9,5$ à 14,4 p. 100) que dans le cas du régime gluten. Comme précédemment, la matière sèche des fractions 4-6 h et 6-8 $\mathrm{h}$ des digesta, mais uniquement dans le cas du régime poisson, apparaît plus riche en AA.

Par rapport aux matières azotées $(\mathrm{N} \times 6,25)$, les $\mathrm{AA}$ représentent une fraction plus stable (69 à 73 p. 100) mais plus modeste dans le cas du poisson que dans celui du gluten ( 82 p. 100 , en moyenne). Pour ce dernier, le pourcentage d'AA dans les matières azotées des contenus subit une diminution au fur et à mesure que s'éloigne le moment du repas expérimental. Par contre, cette évolution n'est pas enregistrée pour le régime protéiprive, bien que la fraction des matières azotées collectées correspondant aux AA soit également importante $(85$ à 91 p. 100).

D'une manière générale, les concentrations en AA de la fraction libre, exprimées par rapport à la matière sèche (du surnageant) sont beaucoup plus faibles que les valeurs précédemment rapportées pour l'ensemble des AA (tabl. 2). Elles apparaissent relativement stables, non assujetties à la source protéique ni au temps de collecte. Exprimés par rapport aux matières azotées du surnageant, les AA libres représentent une fraction modeste (10 à 15 p. 100), légèrement plus importante dans le cas du gluten de blé. 


\section{TABleau 1}

Moyennes et écarts-type à la moyenne des quantités d'AA (g)

recueillies à chacun des temps de collecte avec les régimes poisson, gluten et protéiprive.

Mean quantities and standard deviations of the mean of $A A(g)$

collected for each period and diet (fish-meal, wheat gluten and protein-free diet).

\begin{tabular}{|c|c|c|c|c|c|}
\hline \multirow{2}{*}{$\begin{array}{c}\Sigma \text { AA g } \\
\text { Temps de collecte } \\
\text { Collection period }\end{array}$} & \multicolumn{2}{|c|}{$\begin{array}{l}\text { Farine de poisson } \\
\text { Fish meal diet }\end{array}$} & \multicolumn{2}{|c|}{$\begin{array}{c}\text { Gluten de blé } \\
\text { Wheat gluten diet }\end{array}$} & \multirow{2}{*}{$\begin{array}{c}\begin{array}{c}\text { Protéiprive } \\
\text { Protein-free } \\
\text { diet }\end{array} \\
\begin{array}{c}\text { Digesta } \\
\text { totaux } \\
\text { Total } \\
\text { digesta }\end{array}\end{array}$} \\
\hline & $\begin{array}{c}\text { Digesta } \\
\text { totaux } \\
\text { Total } \\
\text { digesta }\end{array}$ & $\begin{array}{l}\text { Fraction } \\
\quad \text { libre } \\
\text { Free } A A \\
\text { fraction }\end{array}$ & $\begin{array}{c}\text { Digesta } \\
\text { totaux } \\
\text { Total } \\
\text { digesta }\end{array}$ & $\begin{array}{l}\text { Fraction } \\
\quad \text { libre } \\
\text { Free } A A \\
\text { fraction }\end{array}$ & \\
\hline o. $4 \mathrm{~h}$ & $\begin{array}{c}\mathrm{a} \\
2,43 \pm 0,94 \\
(4)\end{array}$ & $\begin{array}{c}0,24 \pm 0,07 \\
\text { (3) }\end{array}$ & $\begin{array}{c}a b \\
0,91 \pm 0,13 \\
(5)\end{array}$ & $\begin{array}{l}0,10 \\
\text { (1) }\end{array}$ & $\begin{array}{c}\mathbf{b} \\
0,68 \pm 0,15 \\
(8)\end{array}$ \\
\hline $4-6 \mathrm{~h}$ & $\begin{array}{c}\mathrm{a} \\
5,25 \pm 0,98 \\
(6) \\
\end{array}$ & $\begin{array}{c}0,46 \pm 0,05 \\
\text { (7) }\end{array}$ & $\begin{array}{c}b \\
1,03 \pm 0,20 \\
(5)\end{array}$ & $\begin{array}{c}0,13 \pm 0,02 \\
*(2)\end{array}$ & $\begin{array}{c}\mathrm{c} \\
0,57 \pm 0,15 \\
(8)\end{array}$ \\
\hline $6-8 \mathrm{~h}$ & $\begin{array}{c}a \\
4,28 \pm 0,91 \\
(6)\end{array}$ & $\begin{array}{c}0,44 \pm 0,09 \\
(7)\end{array}$ & $\begin{array}{l}\mathbf{b} \\
1,06 \pm 0,25 \\
(5)\end{array}$ & $\begin{array}{c}0,17 \pm 0,01 \\
* \text { (3) }\end{array}$ & $\begin{array}{c}\mathrm{b} \\
1,08 \pm 0,34 \\
(9)\end{array}$ \\
\hline $8-14 \mathrm{~h}$ & $\begin{array}{c}\mathrm{a} \\
7,72 \pm 0,76 \\
\quad(6) \\
\end{array}$ & $\begin{array}{c}0,69 \pm 0,07 \\
\text { (7) }\end{array}$ & $\begin{array}{c}\mathrm{b} \\
2,82 \pm 0,35 \\
(5)\end{array}$ & $\begin{array}{c}0,34 \pm 0,04 \\
*(5)\end{array}$ & $\begin{array}{c}\mathrm{b} \\
2,73 \pm 0,43 \\
(9)\end{array}$ \\
\hline $14-24 \mathrm{~h}$ & $\begin{array}{c}\mathrm{a} \\
4,85 \pm 0,84 \\
\quad(6)\end{array}$ & $\begin{array}{c}0,35 \pm 0,06 \\
(7)\end{array}$ & $\begin{array}{c}\mathrm{b} \\
2,54 \pm 0,36 \\
(5)\end{array}$ & $\begin{array}{c}0,23 \pm 0,04 \\
\text { (4) }\end{array}$ & $\begin{array}{c}\mathrm{b} \\
3,20 \pm 0,40 \\
(9)\end{array}$ \\
\hline $\begin{array}{l}\text { En } 24 \mathrm{~h} \\
\text { Over } 24 \mathrm{~h}\end{array}$ & $\begin{array}{c}a \\
23,83 \pm 1,33 \\
\text { (6) }\end{array}$ & $\begin{array}{c}2,04 \pm 0,16 \\
\text { (7) }\end{array}$ & $\begin{array}{c}\mathrm{b} \\
8,25 \pm 0,67 \\
(5)\end{array}$ & 0,97 & $\begin{array}{c}\mathrm{b} \\
8,12 \pm 0,60 \\
\text { (9) }\end{array}$ \\
\hline
\end{tabular}

Le nombre de données individuelles figure entre parenthèses.

Pour les digesta totaux, les valeurs affectées de lettres différentes sur une même ligne diffèrent entre elles au seuil $\mathrm{p}<0,10$.

Pour les fractions libres, la présence d'un astérisque indique que les 2 valeurs d'une même ligne diffèrent entre elles au seuil $\mathrm{p}<0,10$.

La valeur indiquée pour la fraction libre des digesta gluten en $24 \mathrm{~h}$ est la somme des valeurs moyennes de chacun des temps de collecte, et non une moyenne des résultats sur 24 h, dans la mesure où aucun nycthémère n'a été complet.

The number of individual data is given between brackets.

For total digesta, values within one and the same line bearing different letters differ $(p<0.10)$.

For the free AA fractions, the star indicates a between diets significant difference $(p<0.10)$.

The $24 \mathrm{~h}$ value given for the free $A A$ fraction of digesta collected with the gluten diet is the sum of the mean values recorded at each collection period, because of lacking measurements for overall $24 \mathrm{~h}$ periods. 


\section{Tableau 2}

Teneurs moyennes en AA de la matière sèche ( $I^{r_{c}}$ ligne) et des matières azotées $\left(2^{c}\right.$ ligne) recueillies à chacun des temps de collecte et dans chacune des fractions.

Mean quantities of $A A$ collected for each period and diet relative to the dry matter (Ist line) and nitrogenous matters (2nd line) of the corresponding fraction.

\begin{tabular}{|c|c|c|c|c|c|}
\hline \multirow{3}{*}{$\begin{array}{l}\Sigma \mathrm{AAg} / 100 \mathrm{~g} \mathrm{M} . \mathrm{S} \\
\Sigma \mathrm{AA} / 16 \mathrm{~g} \mathrm{~N} \\
\text { Temps de collecte } \\
\text { Collection period }\end{array}$} & \multicolumn{2}{|c|}{$\begin{array}{l}\text { Gluten de blé } \\
\text { Wheat gluten diet }\end{array}$} & \multicolumn{2}{|c|}{$\begin{array}{l}\text { Farine de poisson } \\
\text { Fish meal diet }\end{array}$} & \multirow{3}{*}{$\begin{array}{c}\text { Protéiprive } \\
\text { Protein free } \\
\text { diet }\end{array}$} \\
\hline & $\begin{array}{l}\text { Digesta } \\
\text { totaux }\end{array}$ & $\begin{array}{l}\text { Fraction } \\
\text { libre }\end{array}$ & $\begin{array}{l}\text { Digesta } \\
\text { totaux }\end{array}$ & $\begin{array}{l}\text { Fraction } \\
\text { libre }\end{array}$ & \\
\hline & $\begin{array}{c}\text { Total } \\
\text { digesta }\end{array}$ & $\begin{array}{c}\text { Free } A A \\
\text { fraction }\end{array}$ & $\begin{array}{c}\text { Total } \\
\text { digesta }\end{array}$ & $\begin{array}{l}\text { Free } A A \\
\text { fraction }\end{array}$ & \\
\hline $0-4 \mathrm{~h}$ & $\begin{array}{l}12,4^{a} \\
72,9^{a}\end{array}$ & $\begin{array}{l}4,5 \\
8,8\end{array}$ & $\begin{array}{r}9,7 \mathbf{a} \\
97,7 \mathrm{~b}\end{array}$ & $\begin{array}{r}5,2(1) \\
10,4(1)\end{array}$ & $\begin{array}{l}13,9^{a} \\
88,3^{b}\end{array}$ \\
\hline 4- $6 \mathrm{~h}$ & $\begin{array}{l}16,0^{a} \\
69,4^{a}\end{array}$ & $\begin{array}{r}6,0 \\
10,1\end{array}$ & $\begin{array}{r}7,0^{\mathrm{l}} \\
94,1^{\mathrm{b}}\end{array}$ & $\begin{array}{l}3,9^{*} \\
12,4\end{array}$ & $\begin{array}{l}12,6^{\mathrm{a}} \\
91,2^{\mathrm{b}}\end{array}$ \\
\hline 6- $8 \mathrm{~h}$ & $\begin{array}{l}16,5^{\mathrm{a}} \\
72,7^{\mathrm{a}}\end{array}$ & $\begin{array}{r}6,1 \\
10,6\end{array}$ & $\begin{array}{r}7,7^{\mathrm{b}} \\
82,7^{\mathrm{b}}\end{array}$ & $\begin{array}{c}6,7 \\
16,2^{*}\end{array}$ & $\begin{array}{l}14,4^{\mathrm{a}} \\
91,1^{\mathrm{b}}\end{array}$ \\
\hline $8-14 \mathrm{~h}$ & $\begin{array}{l}12,1^{\mathrm{a}} \\
69,9^{\mathrm{a}}\end{array}$ & $\begin{array}{r}6,1 \\
12,1\end{array}$ & $\begin{array}{r}8,0^{\mathrm{b}} \\
75,4^{\mathrm{b}}\end{array}$ & $\begin{array}{c}6,4 \\
18,4^{*}\end{array}$ & $\begin{array}{l}9,5^{\mathrm{al}} \\
90,2^{\mathrm{c}}\end{array}$ \\
\hline $14-24 \mathrm{~h}$ & $\begin{array}{l}10,6^{\mathrm{a}} \\
73,4^{\mathrm{a}}\end{array}$ & $\begin{array}{l}3,7 \\
9,4\end{array}$ & $\begin{array}{r}7,0^{\mathrm{b}} \\
79,8^{\mathfrak{a}}\end{array}$ & $\begin{array}{r}4,1 \\
11,3\end{array}$ & $\begin{array}{l}10,7^{\mathrm{a}} \\
85,5^{\mathrm{a}}\end{array}$ \\
\hline $\begin{array}{c}\text { en } 24 \mathrm{~h} \\
\text { over } 24 h\end{array}$ & $\begin{array}{l}13,1^{\mathrm{a}} \\
72,0^{\mathrm{a}}\end{array}$ & $\begin{array}{r}5,5 \\
10,3\end{array}$ & $\begin{array}{r}7,6^{b} \\
81,6^{b}\end{array}$ & $\begin{array}{c}5,1 \\
14,7^{*}\end{array}$ & $\begin{array}{l}10,3^{\mathrm{c}} \\
86,4^{\mathrm{b}}\end{array}$ \\
\hline
\end{tabular}

Sur une même ligne, la signification des lettres et des astérisques est la même que dans le tableau 1.

Within one and the same line, the letters and stars have the same meaning as in table 1.

(1) Une seule valeur individuelle - Only one individual value.

Dans l'évolution en AA des contenus digestifs collectés, la part des EAA (tabl. 3) s'avère relativement constante avec les régimes protéiprive ou gluten $(52,6 \mathrm{p}$. 100). Par contre, dans le cas du régime poisson, cette fraction élevée en EAA (51,2 à 52 p. 100) n'est retrouvée que durant les périodes où le flux des AA est faible $(0-4 \mathrm{~h}, 14-24 \mathrm{~h})$. La part des EAA dans les AA libres, s'avère moindre que dans le cas précédent (AA totaux) sans qu'une réelle différence ne se dégage entre les deux sources protéiques. 
TABLEAU 3

Proportions d'acides aminés essentiels (EAA en $\mathrm{g} / 100 \mathrm{~g}$ d'AA totaux) dans les digesta recueillis à chacun des temps de collecte, avec les régimes poisson

(digesta totaux et fraction libre), gluten (digesta totaux et fraction libre)

et protéiprive (digesta totaux).

Proportion of essential amino acids ( $E A A$ as $\mathrm{g} / 100 \mathrm{~g}$ of total $A A$ )

in the digesta collected for each period and diet.

Fish meal diet - Wheat gluten diet (Total digesta and free AA fraction) Protein free diet (Total digesta).

\begin{tabular}{|c|c|c|c|c|}
\hline \multicolumn{2}{|c|}{$\begin{array}{l}\text { Temps de collecte } \\
\text { Collection period }\end{array}$} & $\begin{array}{l}\text { Farine de poisson } \\
\text { Fish-meal diet } \\
\text { EAA \% } \% \text { AA }\end{array}$ & $\begin{array}{l}\text { Gluten de blé } \\
\text { Wheat gluten diet } \\
\text { EAA \% इAA }\end{array}$ & $\begin{array}{c}\text { Protéiprive } \\
\text { Protein-free diet } \\
\text { EAA \% } \Sigma \text { AA }\end{array}$ \\
\hline $0+4 \mathrm{~h}$ & $\begin{array}{l}\text { Digesta totaux } \\
\text { Total digesta } \\
\text { AA libres .... } \\
\text { Free } A A\end{array}$ & $\begin{array}{l}52,0^{\mathrm{a}} \\
49,6^{\mathrm{a}}\end{array}$ & $\begin{array}{l}53,3^{\mathrm{a}} \\
*^{*} \\
48,0^{\mathrm{a}} \text { (1) }\end{array}$ & $\begin{array}{r}53,1^{\mathrm{a}} \\
-\end{array}$ \\
\hline 4- $6 \mathrm{~h}$ & $\begin{array}{l}\text { Digesta totaux } \\
\text { Total digesta } \\
\text { AA libres .... } \\
\text { Free } A A\end{array}$ & $\begin{array}{l}42,1^{\mathrm{a}} \\
34,8^{\mathrm{a}}\end{array}$ & $\begin{array}{r}53,3^{b} \\
* \\
41,7^{a}\end{array}$ & $\begin{array}{r}53,8^{b} \\
-\end{array}$ \\
\hline $6-8 \mathrm{~h}$ & $\begin{array}{l}\text { Digesta totaux } \\
\text { Total digesta } \\
\text { AA libres ... } \\
\text { Free } A A\end{array}$ & $\begin{array}{l}41,3^{\mathrm{a}} \\
35,6^{\mathrm{a}}\end{array}$ & $\begin{array}{r}51,8^{\mathrm{b}} \\
* \\
42,4^{\mathrm{a}}\end{array}$ & $\begin{array}{r}53,2^{b} \\
-\end{array}$ \\
\hline $8-14 \mathrm{~h}$ & $\begin{array}{l}\text { Digesta totaux } \\
\text { Total digesta } \\
\text { AA libres .... } \\
\text { Free } A A \\
\end{array}$ & $\begin{array}{c}44,3^{\mathrm{n}} \\
* \\
29,4^{\mathrm{a}}\end{array}$ & $\begin{array}{r}52,5^{b} \\
* \\
38,2^{b}\end{array}$ & $\begin{array}{r}53,0^{\mathrm{b}} \\
-\end{array}$ \\
\hline $1424 \mathrm{~h}$ & $\begin{array}{l}\text { Digesta totaux } \\
\text { Total digesta } \\
\text { AA libres .... } \\
\text { Free AA }\end{array}$ & $\begin{array}{l}51,2^{\mathfrak{a}} \\
* \\
35,6^{\mathrm{a}}\end{array}$ & $\begin{array}{r}53,3^{b} \\
* \\
41,6^{a}\end{array}$ & $\begin{array}{c}52,2^{\mathrm{ab}} \\
-\end{array}$ \\
\hline $\begin{array}{l}\text { En } 24 h \\
\text { Over } 24 h\end{array}$ & $\begin{array}{l}\text { Digesta totaux } \\
\text { Total digesta }\end{array}$ & * $32,5 \mathrm{a}$ & $40,0^{*}$ & $52,7^{b}$ \\
\hline
\end{tabular}

(1) Une seule valeur individuelle - Only one individual value.

Sur une même ligne (digesta totaux ou fraction libre), la signification des lettres est la même que dans les tableaux 1 et 2 .

Sur une même colonne et un temps de collecte donné, la présence d'un astérisque indique que les proportions observées dans les digesta totaux et dans la fraction libre diffèrent entre elles au seuil $\mathrm{p}<0,10$.

Within one and the same line (total digesta or free AA fraction) the letters have the same meaning as in tables 1 and 2 .

Within one column and one collection period, the star indicates a significant difference between the proportions observed in total digesta and in the free AA fraction $(p<0.10)$. 


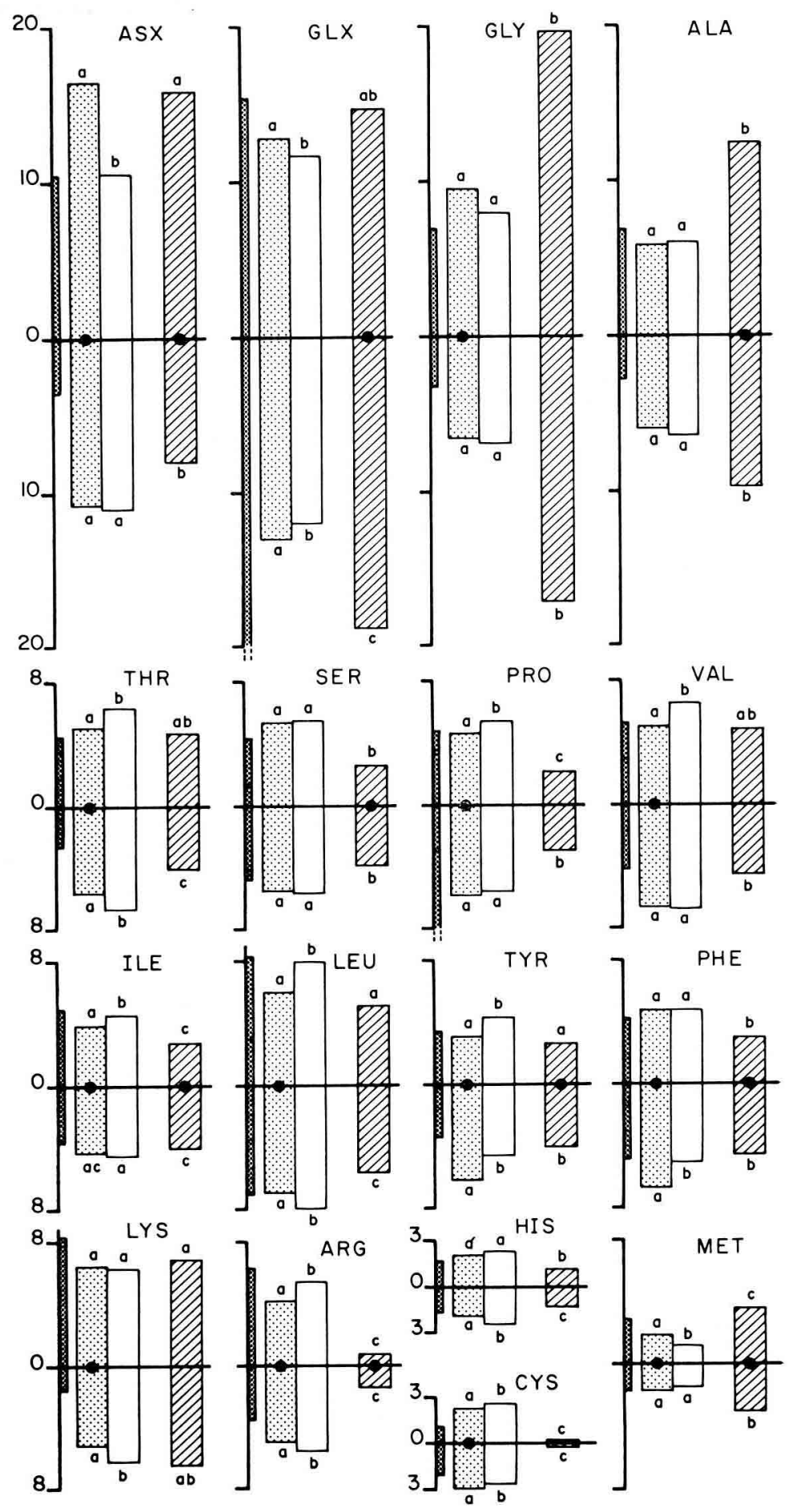

FIG. 1 


\section{B. Variations de la composition des digesta en acides aminés individuels}

\section{Composition moyenne des digesta recueillis en 24 heures (fig. 1)}

Les données rapportées précédemment (DARCY, Laplace \& DuÉE, 1982) permettent de dresser le profil en AA des digesta collectés sur la totalité du nycthémère (teneurs en AA exprimées en pourcentage de leur somme).

Parmi le groupe des EAA, LEU, LYS, VAL et THR, prédominent, tandis que dans le groupe des NAA les di-acides (ASX et GLX) ainsi que GLY présentent les teneurs. relatives les plus élevées. Certaines différences apparaissent selon la nature de la source de protéines alimentaires. Les teneurs relatives en EAA sont plus élevées dans le cas du gluten de blé ; cette particularité résulte d'une teneur plus élevée des contenus digestifs en AA aromatiques et à chaîne ramifiée. Toutefois, la teneur relative en LYS est plus faible. Par ailleurs, le rapport des concentrations MET/CYS varie considérablement d'un régime à l'autre $(0,95$ dans le cas de la farine de poisson; 0,55 dans l'autre cas), du fait de teneurs plus faibles en MET et plus élevées en CYS avec le régime gluten. Enfin, pour ce même régime, l'ensemble des teneurs en NAA est plus faible du seul fait des teneurs en ASX et GLY.

Les profils de composition en AA obtenus lors des repas protéiprives (après l'un ou l'autre des régimes azotés) sont tout à fait similaires, sauf peut-être dans le cas de GLY, sans que cette différence soit significative. En comparant les données obtenues en régime protéiprive et celles concernant le régime gluten, peu de divergences apparaissent : elles ne portent que sur le groupe des EAA parmi lesquels LEU, LYS, THR et HIS ont des teneurs plus élevées, tandis que les AA aromatiques ont des teneurs plus faibles lors du repas protéiprive. Par contre, les profils d'AA établis en régime

FIG. I

Composition moyenne des digesta collectés en $24 \mathrm{~h}$ (chaque AA est exprimé en p. 100 de la somme des AA déterminés).

Mean AA composition of digesta collected within $24 \mathrm{~h}$ (each $A A$ is expressed as $p .100$ of the total $A A$ assayed).

Aliment.

Dietary protein.

Digesta recueillis en régime azoté (AA totaux).

Digesta collected with nitrogenous diets (total AA).

Digesta recueillis en régime protéiprive (AA totaux).

Digesta collected with protein-free diet (total $A A)$.

Fraction AA libres des digesta recueillis en régime azoté.

Free $A A$ fraction of digesta collected with nitrogenous diets.

Demi graphique supérieur : régime «poisson " et régime protéiprive distribué après “poisson" Top of the graph : fish-meal diet and protein-free diet following fish meal.

Demi-graphique inférieur : régime "gluten " et régime protéiprive distribué après « gluten " - Bottom of the graph: wheat-gluten diet and protein-free diet following wheat-gluten.

Pour chaque demi-graphique. les valeurs affectées d'une lettre différente diffèrent entre elles au seuil $\mathrm{p}<0,10$ - For each part of the graphs, the columns bearing different letters differ accorling to Student's t test $(p<0.10)$.

?our chaque colonne, la présence d'un point indique une différence entre régimes $(p<0,10)-$ Within each column, the point indicates the between-diets differences $(p<0.10)$. 
protéiprive et en régime poisson présentent des différences systématiques : les teneurs relatives en EAA sont plus faibles après le repas protéique qu'après le repas protéiprive, sauf pour MET ct secondairement LYS; en revanche, la teneur en ASX est plus élevée.

La composition relative des fractions correspondant aux AA libres des digesta semble, d'une manière générale, très différente de celle des contenus totaux. Leur richesse en NAA porte principalement sur GLY, ALA et GLX, tandis qu'ils ont une faible teneur en la plupart des EAA, sauf LYS et MET. Ainsi, les teneurs relatives en ARG et en CYS de la fraction libre sont particulièrement faibles. Les différences de composition en AA, observées précédemment entre les contenus totaux correspondant aux 2 aliments protéiques, subsistent dans les fractions libres, mais d'une manière plus modérée.

Enfin, si l'on confronte la composition en AA des digesta à celles des sources protéiques consommées, de profondes divergences existent. Dans le cas de la farine de poisson, les contenus digestifs s'appauvrissent en EAA, et plus particulièrement en LYS,

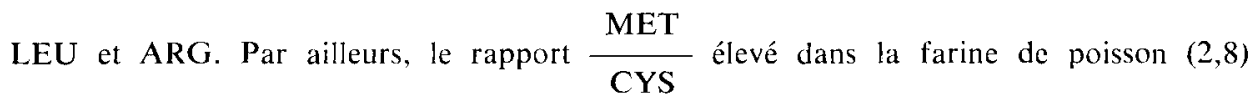

est considérablement abaissé, comme cela a été précisé précédemment. Lcs contenus digestifs s'enrichissent par contre en NAA et ceci touche plus spécifiquement ASX et GLY. Dans le cas du gluten de blé, source protéique à faibles teneurs en EAA (36 p. 100 des AA totaux), on enregistre une augmentation considérable des teneurs correspondantes dans les contenus digestifs. Inversement, les contenus digestifs présentent des concentrations en NAA réduites et plus particulièrement GLX et PRO dont l'apport par le gluten de blé est pourtant considérable.

\section{Profils des acides aminés des contenus à chacun des temps de collecte (fig. 2)}

Après consommation d'un régime protéiprive, la composition en AA des contenus d'iléon varie peu selon le moment de la collecte, sauf pour GLY dont la teneur augmente dans la seconde moitié du nycthémère. La consommation du régime gluten se traduit par une composition des digesta en AA, qui présente un certain nombre de différences par rapport à celle observée avec le régime protéiprive. Les écarts de composition pour chaque EAA se maintiennent à tout moment du nycthémère. Toute-

\section{FIG. 2}

Composition moyenne des digesta collectés à chacun des temps post-prandiaux successifs (chaque AA est exprimé en p. 100 de la somme des AA déterminés).

Mean AA composition of digesta collected at each of the following collections (each $A A$ is expressed as p. 100 of the sum of the AA assayed).

Les colonnes de gauche à droite représentent dans l'ordre les temps 0 à 4 h, 4 à 6 h, 6 à 8 h, 8 à $14 \mathrm{~h} .14$ à $24 \mathrm{~h}$ après le repas - The columns indicate, from left to right, the following périods : $0-4 h, 4-6 h, 6-8 h, 8-14 h, 14-24 h$ after the meal.

Digesta recueillis en régime azoté.

Digesta collected with the nitrogenous diets.

Digesta recueillis en régime protéiprive.

Digesta collected with the protein free-diet.

Les demi-graphiques supérieur et inférieur. les lettres et les points ont la même signification que dans la fig. 1 - The upper and lower parts of the graphs, the letters and the points have the same meaning as in fig. $l$. 

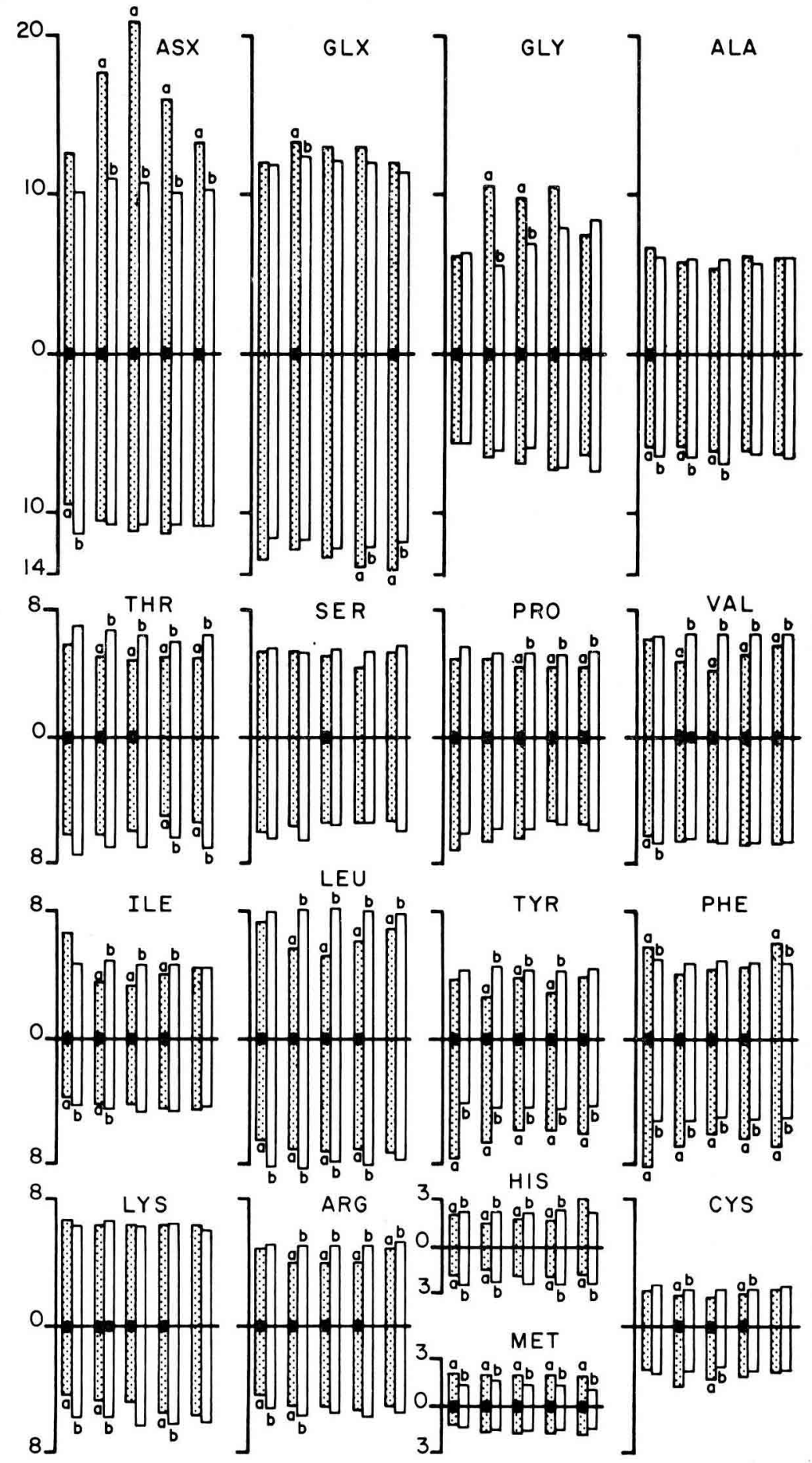

FIG. 2 

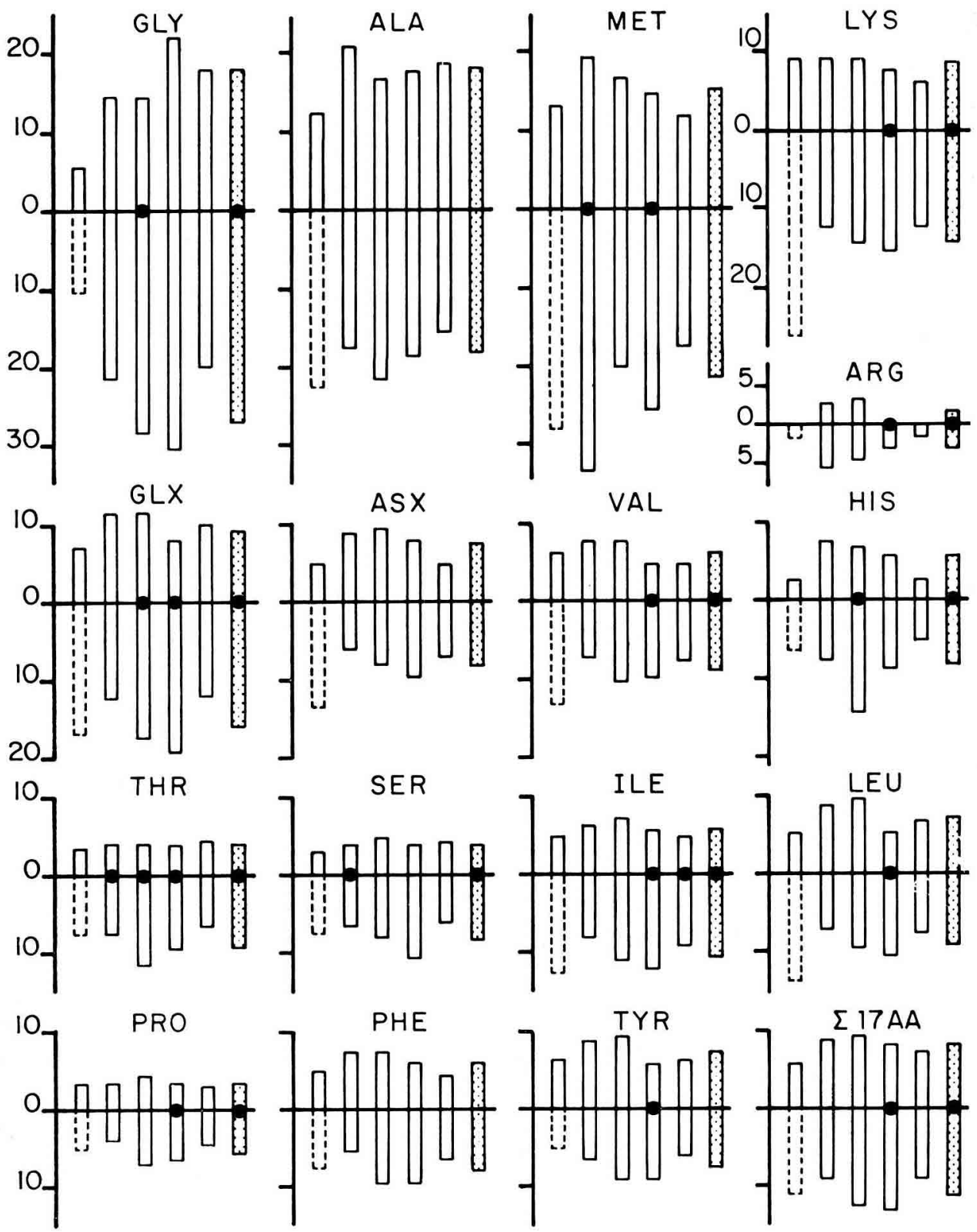

FIG. 3

Proportion des AA présents sous forme libre dans les digesta collectés à chacun des temps post-prandiaux successifs.

Proportion of the AA present in the free form in digesta collected at each period. 
fois, en régime gluten, les teneurs en AA aromatiques sont particulièrement élevées dans le premier tiers du nycthémère, et la teneur en LYS est faible. Pour LEU, un écart significatif entre les deux types de contenus est maintenu jusqu'à $14 \mathrm{~h}$ après le repas ; par contre, pour THR, les différences ne s'accentuent que dans la seconde moitié du nycthémère. En définitive, hormis le cas de ce dernier $\mathrm{AA}$, les divergences de composition en EAA des deux contenus digestifs s'amenuisent à la dernière période de collecte (14-24 h). Pour ce qui concerne les NAA, les différences de composition des digesta pour ces deux régimes sont plus variables d'une collecte à l'autre. On notera toutefois une augmentation de la teneur en ASX au cours du nycthémère dans les contenus gluten, compensée par une diminution rapide de la teneur en PRO.

La consommation du régime poisson modifie d'une manière différente la composition en AA des contenus digestifs, surtout si on la compare à la composition correspondante obtenue en régime protéiprive. Les concentrations d'un certain nombre d'EAA (THR, VAL, ILE, LEU, TYR et ARG) sont particulièrement réduites entre 4 et $14 \mathrm{~h}$ après le repas. Pour LYS, par contre, il ne ressort pas d'évolution selon la période de collecte; il en est de même pour MET, la richesse relative des digesta en cet AA paraissant permanente en régime poisson. Dans le groupe des NAA, un enrichissement relatif en certains d'entre eux (ASX, GLY) est mis en évidence dans les collectes couvrant la période 4-14 h.

Les écarts de composition entre les deux sources protéiques, détectés lors de la comparaison des contenus digestifs recouvrant un nycthémère complet se retrouvent dans une certaine mesure au cours de chaque collecte ; ces écarts apparaissent cependant accentués au début du nycthémère $(0-4 \mathrm{~h})$ pour TYR, PHE et PRO, et aux périodes suivantes (4-6 h, 6-8 h, 8-14 h) pour VAL, LEU, LYS, ASX et GLY.

3. Evolution post-prandiale de la proportion des acides aminés sous forme libre dans les contenus digestifs (fig. 3)

La proportion moyenne d'AA sous forme libre s'élève à 8,5 p. 100 pour les contenus poisson, contre 11 p. 100 pour les contenus gluten. Cette proportion est élevée pour trois d'entre eux (GLY, ALA, MET). Dans le cas du gluten, l'importance de la fraction libre des AA est imputable à un certain nombre d'entre eux (GLY, MET,

Les colonnes de gauche à droite correspondent aux temps de collecte successifs, comme dans la figure 2.

La colonne grisée représente la proportion moyenne observée sur l'ensemble des $24 \mathrm{~h}$.

Les demi-graphiques supérieurs se rapportent au régime poisson et les demi-graphiques inférieurs au régime gluten. La signification des points est la même que dans les figures 1 et 2 .

La colonne en pointillés correspond au temps 0 à $4 \mathrm{~h}$ en régime gluten pour lequel une valeur unique est rapportée.

The columns from left to right illustrate the following collection periods, as in figure 2.

The dotted column illustrates the mean proportion recorded within $24 \mathrm{~h}$.

Top of the graphs : fish meal diet.

Bottom of the graphs : wheat gluten diet.

The points have the same meaning as in figures 1 and 2.

The column with dotted lines $(0.4 \mathrm{~h}$ with the wheat gluten diet) corresponds to only one individual value. 

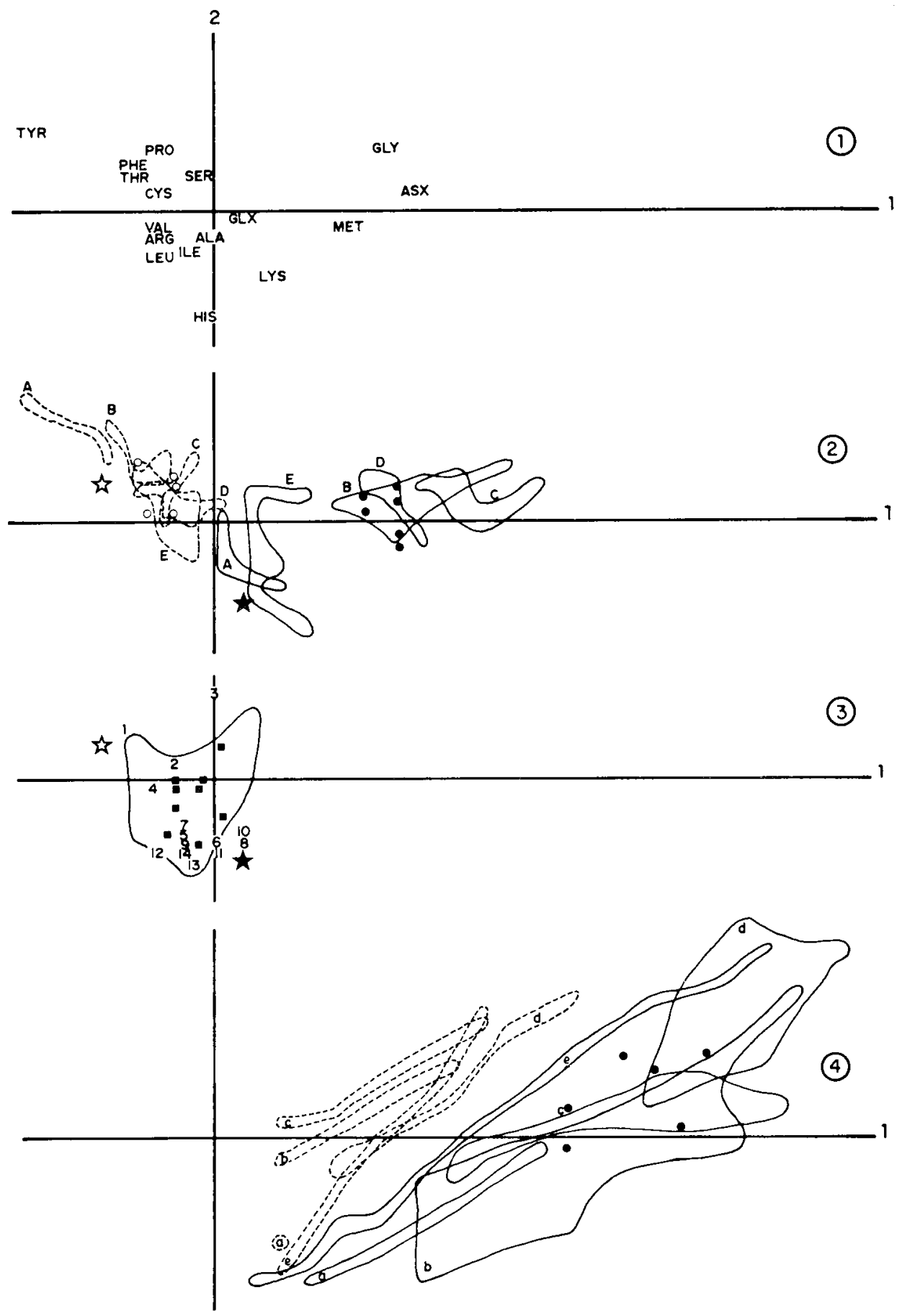

FIG. 4 
FIG. 4

Représentation graphique des résultats de l'analyse factorielle des correspondances,
dams le plan défini par les deux premiers facteurs.

Graphical representation of the results of the factorial analysis of correspondances (plane dofined by the first and second factorial axes).

1: Représentation des 17 points AA.

Representation of the 17 AA points.

2: Aires de projection des points-échantillons individuels représentant les digesta totaux collectés en régime azoté.

Projection areas of the individual sample-points representing total digesta collected with nitrogenous diets.

$\star$ - Régine poisson.

Fish meal diet.

t: .... Régime gluten.

Wheat gluten diet.

Temps de collecte - Collection period :

A : $0-4 h$
B : $4-6 h$
C $: 6-8 h$
D $: 8-14 h$
E $: 14-24 h$

après le repas - following the meal.

Les points $(\bullet, O)$ représentent les résultats individuels obtenus pour les digesta de $24 \mathrm{~h}$.

Les étoiles $(\star, \%)$ représentent la composition des protéines alimentaires.

The points (O) illustrate the individual results for the $24 \mathrm{~h}$ digesta.

The stars ( $\star,+)$ illustrate the composition of the dietary proteins.

3 : Aires de projection des points-échantillons individuels représentant les digestat totaux collectés en régime protéiprive.

La liste des échantillons de référence introduits dans l'analyse est rapportéc en annèxe. Les étoiles et les carrés (耳) ont la même signification que dans la partie 2.

Projection areas of the individual sample-points representing total digesta collected with protein-free diet.

The reference sample-points are listed in annexe.

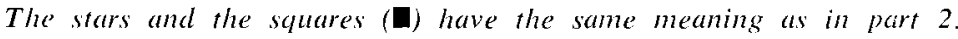

4: Aires de projection des points-échantillons inclividuels représentant la liaction AA libres des digesta collectés en régime azoté.

Les points et les lettres ( $a, b, c, d, e)$ ont la même signification que dans la partie 2. Projection areas of the individual sample-points representing the free AA fraction of digesta collected with nitrogenous diets.

The points and the letters ( $a, b, c, d$, e) have the same meaning as in part 2. 
LYS, GLX, THR, SER, ILE et PRO). Cette proportion plus élevée dans le cas du gluten de blé, semble se manifester lors de chacune des périodes de collecte. Indépendamment de la source protéique, on observe globalement un accroissement de la fraction libre entre 6 et $8 \mathrm{~h}$ après le repas d'épreuve, suivi d'une diminution. L'évolution postprandiale n'est pas uniforme pour chacun des AA. L'augmentation au cours du premier tiers du nycthémère affecte un large éventail d'AA (LEU, VAL, ILE, TYR, PHE, MET, HIS, ASX, GLX et ALA). Pour GLY, l'enrichissement de la fraction libre est maintenu jusqu'à $14 \mathrm{~h}$ après le repas.

\section{Analyse multidimensionnelle des variations de composition}

L'analyse factorielle des correspondances porte sur 113 échantillons (AA totaux des digesta pour les 3 régimes). Les 6 premiers facteurs permettent d'expliquer 92,6 p. 100 de la variance totale. Cependant, les deux premiers supportent 64 p. 100 de la variance; la prise en compte du troisième axe permet d'en expliquer au total 78 p. 100. Nous nous limiterons donc à l'examen des 3 premiers facteurs. La figure 4 présente les projections des variables (les AA) et des échantillons sur le plan défini par les axes 1 et 2 .

Le premier axe est déterminé (fig. 4-1) d'un côté par la forte contribution de ASX (39,5 p. 100 de la variance expliquée par l'axe 1) et GLY (18,7 p. 100) et à l'opposé par la contribution de TYR (15,6 p. 100). Aux fortes contributions d'ASX et GLY correspondent (fig. 4-2) de fortes contributions des échantillons de digesta collectés en régime poisson entre 4 et $14 \mathrm{~h}$, et des échantillons moyens de $24 \mathrm{~h}$. A la forte contribution de TYR correspond principalement la forte contribution des échantillons de digesta collectés en régime gluten entre 0 et $4 \mathrm{~h}$. Ces correspondances traduisent la proportion relative élevée de ces AA dans les échantillons concernés. L'ensemble des points échantillons de digesta recueillis en régime protéiprive se situe au voisinage du point moyen (fig. 4-3). Les points supplémentaires correspondant aux échantillons références (sources endogènes) se projettent sur le même segment de l'axe 1 que les digesta recueillis en régime protéiprive. La projection des points supplémentaires correspondant aux AA libres des digesta montre une plus grande proximité des digesta pour les régimes gluten et poisson (fig. 4-4) que dans le cas des AA totaux. La forte proportion d'ASX et GLY pour les échantillons poisson est encore plus marquée dans le cas des AA libres. Ces mêmes AA semblent aussi peser fortement dans le cas des AA libres des digesta gluten.

Le deuxième axe est déterminé (fig. 4-1) par les contributions de TYR et GLY (chacun 13,2 p. 100 de la variance liée à l'axe) d'un côté et de LYS (15,5 p. 100), HIS (13,5 p. 100) et LEU (10 p. 100) de l'autre. Une forte contribution de GLY correspond à une forte proportion de cet AA dans certains échantillons collectés entre 4 et $6 \mathrm{~h}$ en régime poisson (fig. 4-2). La contribution élevée de TYR correspond aux échantillons de la période $0-4 \mathrm{~h}$ en régime gluten. A l'opposé les fortes contributions de LYS, HIS, LEU correspondent à la plupart des échantillons collectés en régime poisson soit entre 0 et $4 \mathrm{~h}$, soit entre 14 et $24 \mathrm{~h}$. Les digesta collectés en régime protéiprive (fig. 4-3) sont aussi caractérisés par leur forte teneur en LYS, HIS, LEU, relativement aux digesta recueillis dans d'autres situations. Dans le cas des AA libres, quel que soit le régime considéré, les échantillons correspondant à une même période de collecte se projettent de part et d'autre du point médian, ce qui ne permet pas d'attribuer de façon régulière un poids particulier à te! ou tel $\mathrm{AA}$. 
Le troisième axe, qui explique encore à lui seul 14 p. 100 de la variance du nuage de points, oppose de fortes contributions de TYR $(17,2$ p. 100) et PHE $(15,4$ p. 100$)$ correspondant aux échantillons en régime gluten et à certains échantillons en régime poisson (0-4 h et 14-24 h), aux fortes contributions de THR (21,4 p. 100) et GLY $(15,5$ p. 100$)$ qui correspondent aux échantillons en régime protéiprive. Ceci revient à dire que l'axe 3 discrimine principalement les échantillons de digesta gluten des échantillons de digesta protéiprive très proches dans le plan défini par les axes 1 et 2 . Cet axe 3 sépare aussi les échantillons références en dissociant les échantillons de protéines bactériennes (plus riches en AA aromatiques) des échantillons strictement endogènes tel que mucus, muqueuse intestinale et sécrétion pancréatique de porc (plus riches en THR et GLY).

\section{Discussion}

\section{A. Aspects méthodologiques}

L'influence de la présence et de la nature des protéines alimentaires sur la composition des digesta iléaux fait l'objet d'observations contradictoires mentionnées en introduction. Ces discordances paraissent devoir être reliées à l'échantillonnage des digesta. La plupart des études mentionnées dans la littérature reposent sur la détermination des AA d'un échantillon représentatif des digesta écoulés pendant une période de $24 \mathrm{~h}$, ayant le plus souvent comporté 2 ou même 3 repas (ZerrowskA, 1973 a ; Zebrowska et al., 1975 ; Low, 1979 a, b ; Wünsche et al., 1979 a). Ce type d'étude convient pour la détermination des digestibilités apparentes des AA (DARCY, 1980), mais ne permet pas de mettre en évidence d'éventuelles variations de composition en AA. Dans le cas de distribution de plusieurs repas, le choix (ZEBrowsKa et al., 1982) d'une cinétique arbitraire plus serrée $(3 \times 8 \mathrm{~h}$ de collecte) se révèle inadapté, en raison de la superposition des vagues de digesta correspondant aux repas. Ces observations justifient le choix dans ce travail d'une chronologie de collecte correspondant à la cinétique effective de passage des digesta d'un seul repas d'épreuve (DARCY, Laplace \& VilLIERS, 1981).

Compte tenu de ce que l'on sait de cette cinétique et de l'importance relative de l'azote endogène dans l'azote total des digesta à certaines périodes postprandiales ( 0 à $4 \mathrm{~h}$ et au-delà de la dixième heure pour les régimes étudiés - LAPLACE, Darcy \& Pons, 1983), il paraît évident que l'on doit distinguer différentes périodes au cours du nycthémère. Ceci laisse supposer a priori l'existence, sinon de variations de composition en AA des digesta, du moins de différences de leur provenance au cours du temps. Or, il n'existe pas actuellement de méthode analytique simple permettant de séparer les fractions exogène et endogène des digesta, principalement en raison de l'hétérogénéité physico-chimique de cette dernière fraction. La technique la plus élaborée dont on dispose actuellement pour faire la part de l'endogène et de l'exogène dans les contenus digestifs est celle du marquage isotopique à l'azote ${ }^{15} \mathrm{~N}$ (Souffrant et al., 1982). Par rapport à l'utilisation de régimes protéiprives, elle permet d'évaluer l'endogène résiduel dans les conditions physiologiques d'alimentation protéique. Mais elle concerne l'azote dans sa totalité, dont la signification peut différer largement de celle des AA, lorsque les quantités d'azote présentes sous forme non protidique sont élevées (DARCY, LAPLACE, DuÉE, 1982). Aussi l'étude des variations de la composition en AA des digesta offre 
un moyen d'évaluer la part respective des fractions exogène et endogène dans les matières azotées résiduelles à l'extrémité distale de l'intestin grêle.

\section{B. Acides aminés individuels des échantillons moyens de 24 heures}

La composition moyenne de nos échantillons de $24 \mathrm{~h}$ peut être comparée à celles observées par d'autres auteurs pour des régimes analogues. Nos résultats en régime poisson coïncident assez bien avec les valeurs trouvées par Low (1979 b) pour un régime associant la farine de poisson à des céréales. Lors d'utilisation d'un gluten de blé, nos résultats présentent quelques différences par rapport à ceux de WüNScHE et al. $(1979 \mathrm{a})$ et en particulier des teneurs plus élevées en AA aromatiques et plus faibles en THR, PRO et GLY. Dans le cas de régimes protéiprives, les compositions décrites dans le présent travail comme dans la littérature sont toutes discordantes. Ces divergences portent surtout sur les teneurs en NAA, d'où résultent des rapports $\frac{\text { EAA }}{\text { NAA }}$

très variables : 0,30 (SAuer, Stothers \& Parker, 1977) ; 0,43 (Holmes et al., 1974); 0,77 (Wünsche et al., 1979 a) ; 1,12 dans notre cas. Dans le cas de nos régimes azotés, l'examen des compositions en AA d'échantillons moyens de 24 h (fig. 1) révèle l'existence de multiples différences selon la source de protéines. Il apparaît aussi des différences de composition en AA des digesta de $24 \mathrm{~h}$ entre régimes azotés et protéiprive, quoique moins nombreuses entre protéiprive et gluten.

\section{Variations des acides aminés individuels au cours des 24 heures}

L'interprétation des variations intra-régime au fil du temps post-prandial, et interrégimes pour chacune des collectes consécutives, est facilitée par l'analyse des correspondances (fig. 4). Il existe une discrimination effective des 17 AA, certains d'entre eux étant particulièrement révélateurs des différences entre échantillons. La projection des échantillons moyens de $24 \mathrm{~h}$ sur le plan $(1,2)$ confirme la nette différence de composition des digesta gluten et des digesta poisson, qui peuvent ainsi être caractérisés par leur richesse relative en certains AA : GLY, ASX et MET pour le poisson par exemple. Mais il y a également une différence de projection des échantillons correspondant aux temps de collectes successifs. Ainsi, dans le cas du régime poisson, la richesse relative en ASX et GLY est le fait des échantillons collectés entre 4 et $14 \mathrm{~h}$ après le repas, ce qui les distingue nettement des 2 autres périodes de collecte. De même, dans le cas du régime gluten, on remarque la grande analogie des échantillons collectés entre 6 et $24 \mathrm{~h}$ alors que les échantillons de la période $0-4 \mathrm{~h}$, s'en distinguent nettement par leur forte teneur en TYR et PHE. Il y a done des différences de composition effectives entre régimes à tous les temps de collecte, comme pour les échantillons moyens de $24 \mathrm{~h}$.

Il existe, en outre, pour un même régime, une évolution caractéristique de la composition des digesta au cours des $24 \mathrm{~h}$ post-prandiales. Mais par rapport à ces échantillons les points représentatifs des protéines alimentaires sont peu explicatifs. En effet, le gluten de blé, du fait de sa composition très particulière, n'est réellement bien représenté qu'au niveau de l'axe 4 , et sa projection sur le plan $(1,2)$ ne rend pas compte de sa distance réelle par rapport aux points échantillons. La farine de poisson, 
médiocrement représentée sur le plan $(1,2)$ a en outre une composition assez voisine de celle de certaines sources endogènes (mucus, muqueuse...).

Les échantillons moyens de $24 \mathrm{~h}$ en régime protéiprive présentent une dispersion un peu plus importante que celle observée pour les échantillons homologues en régime azoté. Néanmoins, l'aire de projection de ces échantillons de digesta en régime protéiprive recouvre assez bien les projections des différentes sources d'endogène. Ceci montre que, dans nos conditions, les digesta recueillis en régime protéiprive constituent au point de vue de leur composition, une bonne image de la plupart des sources protéiques endogènes ou microbiennes. Or la projection des échantillons protéiprives recouvre celle des échantillons 0 à $4 \mathrm{~h}$ et 14 à $24 \mathrm{~h}$ en régime poisson, ce qui suggère que ces digesta comportent une forte proportion de ces protéines. Elle recouvre aussi assez largement la zone de projection des échantillons gluten de 4 à $24 \mathrm{~h}$.

\section{Hypothèses sur la provenance des acides aminés résiduels}

Ces observations conduisent à s’interroger sur l'origine de ces variations de composition. Il existe une variation post-prandiale caractéristique du débit d'AA, superposable aux cinétiques de passage antérieurement établies pour la matière sèche et lazote (Darcy, Laplace \& Villiers, 1981). Pour le régime gluten comme pour le régime protéiprive, il n'y a qu'une très faible augmentation du débit d'AA entre 4 et $14 \mathrm{~h}$. Cette similitude correspond bien à la digestibilité quasi-totale des AA du régime gluten (Darcy, Laplace \& DuéE, 1982). A linverse, en régime poisson, il y a une vague de passage d'AA très marquée entre 4 et $14 \mathrm{~h}$, qui traduit très certainement le passage de matériaux exogènes, compte tenu de la moins bonne digestibilité des AA de ce régime (Darcy, Laplace \& DuéE, 1982). Mais les points représentatifs des temps 4 à $14 \mathrm{~h}$ sont distants des points endogènes mais aussi du point représentant le régime poisson. On doit donc faire l'hypothèse que ces digesta, caractérisés par leur richesse en ASX et GLY, sont constitués principalement par des matériaux exogènes résiduels dont la composition diffère de celle de l'aliment. Ils correspondraient à une fraction non digérée de la farine de poisson, de composition particulière. Seule une expérience d'hydrolyse in vitro de l'aliment, suivie d'une détermination des AA des fractions les plus résistantes permettrait de confirmer cette hypothèse. Signalons toutefois que des résultats analogues ont été obtenus in vitro (FORD, 1973) et également in vivo (Buraczewski et al., 1967) pour des protéines de muscle de poisson, soumis à différents traitements thermiques. Ces auteurs ont déterminé la composition en AA des fractions protéiques non digérées; elles sont riches en GLX, ASX, PRO, LYS, MET, GLY et pauvres en LEU, TYR, PHE, ARG et HIS.

Dans le cas ciu régime gluten, les digesta recueillis entre 0 et $4 \mathrm{~h}$ se distinguent des digesta obtenus en régime protéiprive ou des différentes sources d'endogène par leur teneur élevée en AA aromatiques et en PRO. Cette période de collecte correspond à un faible débit de digesta. On sait toutefois d'un point de vue cinétique que le gluten de blé fait l'objet d'une évacuation gastrique initialement rapide (LAPLACE et al., 1981) et qu'il conduit également à une arrivée plus précoce des digesta à la jonction iléocaeco-colique que dans le cas du régime poisson (Laplace, Darcy \& Pons, 1983). Là aussi on peut formuler l'hypothèse du passage d'une fraction d'origine exogène, de composition particulière, différant de celle de l'aliment. Différentes fractions protéiques ont été mises en évidence dans le cas du gluten de blé et caractérisées quant à leur poids moléculaire et à leur composition en AA (ChARBonnier, 1973 et 1974). Les données 
obtenues durant la période $0-4 \mathrm{~h}$ pourraient correspondre à la présence de certaines de ces fractions particulièrement riches en PRO, TYR, PHE mais pauvres en LYS et CYS (fractions de l' $\omega$-gliadine, par exemple). Les données obtenues durant la période suivante (4-6 h), si elles montrent déjà un poids plus important de l'azote d'origine endogène, ne peuvent toutefois permettre d'exclure la présence de fractions protéiques d'origine alimentaire proches des gluténines, plus riches en AA basiques et en CYS. Les points représentatifs des temps 6 à $24 \mathrm{~h}$ se rapprochent encore des points correspondant aux protéines endogènes, ce qui suggère leur prépondérance dans les digesta correspondants, en accord avec la digestibilité quasi-totale des protéines du gluten de blé à l'extrémité distale de l'intestin grêle (DARCY, LAPlace \& DuéE, 1982).

\section{E. Estimation de la contribution respective des fractions exogène et endogène à la composition des digesta}

On peut tenter d'estimer, pour chacun des régimes et des intervalles de collecte, la composition théorique la mieux ajustée à la moyenne des observations et la valeur correspondance de la distance du $\chi^{2}$ (tabl. 4). Pour les échantillons de $24 \mathrm{~h}$, l'ajustement le plus médiocre est obtenu pour le régime poisson et le meilleur dans le cas du régime protéiprive. Pour les collectes consécutives effectuées au cours des $24 \mathrm{~h}$ en régime poisson, les compositions théoriques calculées sont les mieux ajustées aux compositions observées pour les périodes 0 à $4 \mathrm{~h}$ et 14 à $24 \mathrm{~h}$. La composition estimée pour ces 2 périodes se caractérise principalement par sa faible proportion d'aliment. Dans le cas du régime gluten, un bon ajustement des compositions estimées et mesurées est obtenu pour les trois périodes de collecte entre 6 et 24 heures. On note pour ce régime que le rôle de l'aliment dans la composition théorique est toujours faible. La composition théorique pour les 3 périodes entre 6 et $24 \mathrm{~h}$ se caractérise par la décroissance de la part du suc pancréatique et l'importance croissante du rôle des protéines bactériennes. Dans le cas du régime protéiprive, l'ajustement des compositions théoriques et observées est satisfaisant pour toutes les périodes de collecte, avec une relative stabilité au cours du temps des compositions estimées. Dans ce cas, le mucus (ou la muqueuse desquamée) rendrait compte de 30 à 50 p. 100 de la composition estimée alors que cette source d'endogène ne paraît pas entrer en ligne de compte dans la composition estimée des digesta pour les régimes azotés quelle que soit la période considérée.

Il faut néanmoins faire des réserves sur la validité de ces estimations qui restent tributaires de l'éventail limité des fractions de référence prises en compte dans le calcul. Il conviendrait sans doute d'utiliser la composition d'un mélange moyen de protéines endogènes résiduelles et surtout celle des diverses fractions d'origine alimentaire mal digérées dont l'existence a été suggérée ci-dessus.

Au total, et pour les 2 régimes, ces variations de composition au cours du temps semblent refléter les variations des proportions respectives d'une part de certaines fractions exogènes non absorbées et d'autre part de fractions endogènes résiduelles dans les digesta iléaux. On doit d'ailleurs souligner que l'existence d'une influence des protéines alimentaires sur la composition des digesta iléaux ne signifie pas que leur composition reflète celle de l'aliment. En effet, l'exogène présent au niveau iléal est résiduel, c'est-à-dire non absorbé et nécessairement de composition différente de celle de l'aliment puisque, comme nous l'avons déjà souligné (DARCY, LAPLACE \& Duée, 1982), l'absorption des AA n'est pas uniforme. 


\section{TABleaU 4}

Estimation des proportions (\%) de protéines alimentaires, endogènes et bactériennes dans les digesta.

Estimated proportions (\%) of dietary, endogenous and bacterial proteins in the digesta collected.

\begin{tabular}{|c|c|c|c|c|c|c|}
\hline $\begin{array}{c}\text { Temps } \\
\text { de collecte } \\
\text { Collection }\end{array}$ & \multicolumn{2}{|c|}{$\begin{array}{l}\text { Régime poisson } \\
\text { Fish meal diet }\end{array}$} & \multicolumn{2}{|c|}{$\begin{array}{l}\text { Régime gluten } \\
\text { Wheat gluten diet }\end{array}$} & \multicolumn{2}{|c|}{$\begin{array}{l}\text { Régime protéiprive } \\
\text { Protein-free diet }\end{array}$} \\
\hline $0-4 \mathrm{~h}$ & $\begin{array}{l}\mathbf{A}=30 \\
\mathbf{B}=40 \\
\mathrm{C}=10 \\
\mathbf{D}=30\end{array}$ & $x^{2(1)}=16$ & $\begin{array}{l}A=10 \\
B=80 \\
C=0 \\
D=10\end{array}$ & $x^{2}=74$ & $\begin{array}{l}\vec{B}=60 \\
\mathrm{C}=30 \\
\mathrm{D}=10\end{array}$ & $\chi^{2}=17$ \\
\hline 4- $6 \mathrm{~h}$ & $\begin{array}{l}\mathrm{A}=60 \\
\mathrm{~B}=40 \\
\mathrm{C}=0 \\
\mathrm{D}=0\end{array}$ & $x^{2}=142$ & $\begin{array}{l}\mathrm{A}=10 \\
\mathrm{~B}=70 \\
\mathrm{C}=0 \\
\mathrm{D}=20\end{array}$ & $\chi^{2}=45$ & $\begin{array}{l}\overline{\mathrm{B}}=50 \\
\mathrm{C}=40 \\
\mathrm{D}=10\end{array}$ & $x^{2}=11$ \\
\hline $6-8 \mathrm{~h}$ & $\begin{array}{l}\mathrm{A}=60 \\
\mathrm{~B}=40 \\
\mathrm{C}=0 \\
\mathrm{D}=0\end{array}$ & $\chi^{2}=200$ & $\begin{array}{l}\mathrm{A}=10 \\
\mathbf{B}=70 \\
\mathrm{C}=0 \\
\mathrm{D}=20\end{array}$ & $x^{2}=24$ & $\begin{array}{l}\vec{B}=40 \\
C=40 \\
D=20\end{array}$ & $\chi^{2}=12$ \\
\hline $8-14 \mathrm{~h}$ & $\begin{array}{l}\mathrm{A}=60 \\
\mathrm{~B}=40 \\
\mathrm{C}=0 \\
\mathrm{D}=0\end{array}$ & $x^{2}=104$ & $\begin{array}{l}A=10 \\
B=50 \\
C=0 \\
D=40\end{array}$ & $x^{2}=26$ & $\begin{array}{l}\bar{B}=40 \\
\mathrm{C}=50 \\
\mathrm{D}=10\end{array}$ & $x^{2}=15$ \\
\hline $14-2.4 \mathrm{~h}$ & $\begin{array}{l}\mathrm{A}=20 \\
\mathrm{~B}=40 \\
\mathrm{C}=0 \\
\mathrm{D}=40\end{array}$ & $x^{2}=36$ & $\begin{array}{l}\mathrm{A}=10 \\
\mathrm{~B}=40 \\
\mathrm{C}=0 \\
\mathrm{D}=50\end{array}$ & $x^{2}=19$ & $\begin{array}{l}\bar{B}=60 \\
C=40 \\
D=0\end{array}$ & $x^{2}=21$ \\
\hline $\begin{array}{l}\text { en } 24 \mathrm{~h} \\
\text { over } 24 h\end{array}$ & $\begin{array}{l}\mathrm{A}=60 \\
\mathrm{~B}=40 \\
\mathrm{C}=0 \\
\mathrm{D}=0\end{array}$ & $x^{2}=95$ & $\begin{array}{l}A=10 \\
B=60 \\
C=0 \\
D=30\end{array}$ & $x^{2}=25$ & $\begin{array}{l}\bar{B}=50 \\
\mathrm{C}=40 \\
\mathrm{D}=10\end{array}$ & $x^{2}=16$ \\
\hline
\end{tabular}

A : Aliment - Dietary proteins.

B : Suc pancréatique - Pancreatic juice.

C : Mucus intestinal - Intestinal mucus.

D : Bactéries fécales - Faecal bacteria.

(1) Distance du $\chi^{2}$ entre les protéines i et j $-\chi^{2}$ distance :

$$
17 \sum_{k=1}^{17} \frac{(\text { AAik }- \text { AAjk })^{2}}{\frac{\text { AAik }+ \text { AAjk }}{2}}
$$

AAik et AAjk sont les pourcentages respectifs de l'AAk dans la somme des 17 AA déterminés dans les protéines $\mathbf{i}$ et $\mathbf{j}$.

$A A i k$ and $A A j k$ are the respective percentages of $A A k$ in the sum of the $17 A A$ assayed in proteins $i$ and $j$. 


\section{F. Fraction acides aminés libres des digesta recueillis avec les régimes poisson et gluten}

Les proportions d'azote total présent sous forme d'azote soluble dans les contenus sont semblables à celles observées pour des régimes purifiés à base de gluten de blé (ZerrowsKa, 1973 a) ou de caséine (ZebrowsKa, 1973 a ; ZebrowsKa et al., 1975 ; Low, 1979 a), malgré les différences de méthode utilisée pour extraire l'azote soluble. Selon ZebrowsKa (1973 b), dans le cas d'un régime gluten, l'azote aminé correspondant à la fraction AA libres représente 37 p. 100 de l'azote total. Dans le cas de notre régime gluten, la somme des AA libres ne représente que 10 à 15 p. 100 des AA totaux. Néanmoins, la composition de la fraction AA libres est assez voisine dans les deux cas avec en particulier des teneurs élevées en GLX, ASX, GLY. On doit souligner la très grande variabilité des compositions en AA libres des digesta correspondant à chaque période de collecte, et à un régime donné, illustrée par la taille des aires de projection des points individuels (fig. 4-4). Il n'est pas possible de déceler une évolution systématique au cours du temps de la composition de cette fraction compte tenu de cette grande variabilité des résultats. Globalement, la fraction AA libres est caractérisée par sa richesse en ASX, GLY, MET et GLX et sa pauvreté en ARG et CYS.

Ainsi, les fractions «AA libres» ont une composition en AA à la fois très particulière et très variable selon les échantillons. Cependant, on ne peut pas interpréter ces variations, en fonction de la source protéique du régime ou du temps écoulé après le repas expérimental, ni les relier à une variation des proportions de constituants d'origine exogène ou endogène. En effet, le calcul de la distance du $\chi^{2}$ montre que les estimations obtenues sont systématiquement très mauvaises. Au total, l'étude de la fraction AA libres est de peu d'intérêt. Ils sont du reste pratiquement négligeables sur un plan quantitatif, puisque ne représentant que 0,5 à 1,2 p. 100 des quantités d'AA ingérées.

\section{Conclusion}

En définitive, l'interprétation des résultats de cette étude à l'aide de méthodes d'analyse mathématique, permettant une expression synthétique des phénomènes, fait ressortir un certain nombre de conclusions :

- L'étude cinétique de la composition en AA des digesta met en évidence des différences de débit d'AA selon la source de protéines du régime; parallèlement, on enregistre des différences de composition des digesta.

- Evaluée à l'extrémité distale de l'intestin grêle, l'influence des protéines alimentaires s'avère importante, même dans le cas d'une protéine hautement digestible comme le gluten; cet effet de la protéine alimentaire sur la composition des digesta est apparent dans les premières heures post-prandiales, pour un tel régime; il apparaît plus tardivement, mais persiste plus de $12 \mathrm{~h}$ après le repas dans le cas de la farine de poisson.

- Toutefois, s'il existe bien une empreinte des protéines alimentaires sur la composition des digesta, cette influence correspond probablement à la présence de certaines fractions protéiques résistantes à la digestion, dans le cas du gluten comme dans le cas du poisson; par ailleurs, des études complémentaires doivent être effectuées pour déterminer la nature de l'azote non protéique résiduel. 
- D'un point de vue pratique, la digestibilité estimée au niveau iléal fournit assurément une image moins tronquée de l'utilisation digestive des AA d'une protéine alimentaire qu'une détermination fécale (Darcy, LAPlace, DuÉE, 1982); mais les conclusions de cette étude plus approfondie montrent que cette image globale correspond à des réalités physiologiques très différentes d'une protéine à l'autre : diversité de nature des fractions protéiques exogènes résiduelles, provenance et proportion variable des diverses fractions endogènes.

Accepté pour publication en mars 1983.

\section{Summary \\ Protein digestion in the small intestine of the pig \\ 2 - Aminoacid composition of digesta : influence of the dietary protein source of a purified maize starch diet and postprandial variations}

The ileal digestibility of amino acids (AA) of a maize starch based diet containing either fish-meal or wheat gluten as a protein source, has been previously reported (DarCY, LAPLACE \& DuÉE, 1982). The present work describes the post-prandial variation (24 h) in the AA composition of digesta collected by post-valvular ileo-colic fistulation after feeding the same 2 diets. The AA composition of digesta actually differed according to the dietary protein source. This was evidenced in the mean $24 \mathrm{~h}$ samples as well as in each of the following collections : 0-4 h, 4-6 h, 6-8 h, 8-14 h, 14-24 h after the meal. The total and free AA composition of digesta was studied by multivariate analysis (factorial analysis of correspondances, fig. 4). This analysis allows one to compare the composition of digesta to those of dietary proteins, endogenous proteins and digesta collected with a protein-free diet. Moreover, an estimation of the proportion of these various protein sources in the ileal digesta can be attempted (tabl. 4).

The influence of dietary protein was large even for a highly digestible source such as gluten. This effect clearly demonstrated in the first postprandial hours for the gluten diet. It was evidenced later for the fish meal diet, but it persisted more than $12 \mathrm{~h}$ after feeding. The influence of dietary protein was probably due to some undigested protein fractions still present at that level. Studying the variations in the AA composition leads to a better understanding of the physiological events which may account for differences in ileal digestibility values. Anyway, this measurement is more adequate than that performed at the faecal level.

\section{Références bibliographiques}

Buraczewska L., Buraczewski S., Horszczaruk F., Jones A.S., Zebrowska T., 1975. An attempt to estimate the endogenous nitrogen content in the digesta of pigs fed on diets with proteins containing hydroxyproline. Rocz. Nauk. Roln., 96 (B), 105-114.

Buraczewski S., BuraczewsKa L., Ford J.E., 1967. The influence of heating of fish proteins on the course of their digestion. Acta Biochim. Pol., 14, 121-133.

Charbonnier L., 1973. Etude des protéines alcoolo-solubles de la farine de blé. Biochimie, $55,1217-1225$.

Charbonnier L., 1974. Isolation and characterization of w-gliadin fractions. Biochim. Biophys. Acta, 359, 142-151.

Combe E., Pion R., 1977. Influence de l'axénie sur la composition en acides aminés des fèces chez le rat et l'agneau. Ann. Biol. anim. Bioch. Biophys., 17, 633-636.

Corring T., Jung J., 1972. The aminoacid composition of pig pancreatic juice. Nutr. Rep. Int., 6, 187-190. 
Dammers J., 1964. Digestibility in the pig. Factors influencing the digestion of the components of the feed and the digestibility of the aminoacids. These Prukkery "West friesland», Hoorn, p. 152. Université Van Leuven Landbouvinstitut.

Darcy B., 1980. Contribution à l'étude de la digestion dans l'intestin grêle chez le porc : étude de l'interaction entre la nature de l'amidon et la source protéique du régime. Thèse Doct. Ing., I.N.A.-P.G., Paris, 107 p.

Darcy B., Laplace J.P., DuéE P.H., 1982. Digestion des protéines dans l'intestin grêle chez le porc. 1 - Digestibilité des acides aminés selon la source des protéines d'un régime à base d'amidon de maïs purifié. Ann. Zootech., 31, 279-300.

Darcy B., Laplace J.P., Villiers P.A., 1981. Digestion dans l'intestin grêle chez le porc. 4 - Cinćtique de passage des digesta au niveau de la jonction iléo-caeco-colique et bilans de la digestion selon la nature de l'amidon et la source de protéines alimentaires. Ann. Zootech., 30, 31-62.

EGGUM B.O., 1973. A study of certain factors influencing protein utilization in rats and pigs. Beretning fra Forsegslaboratoriet, 406, 173 p.

FORD J.E., 1973. Some effects of processing on nutritive value. In : ROLLS and PorTER J.W.G., Protein in human nutrition, 515-529, Academic Press, New York.

Guilloteau P., Patureau-Mirand P., Toullec R., Prugnaud J., 1980. Digestion of milk protein and methancl-grown bacteria protein in the preruminant calf. 2 - Aminoacid composition of ileal digesta and faeces and blood levels of free aminoacids. Reprod. Nutr. Develop., 20, 615-629.

Gullloteau P., Sauvant D., Patureau-Mirand P., 1983. Methods of comparing aminoacid composition of proteins : application to undigested proteins in the preruminant calf. Ann. Nutr. Metab. (sous presse).

Holmes J.H.G., Bayley H.S., Leadbeater P.A., Horney F.D., 1974. Digestion of protein in small and large intestine of the pig. Br. J. Nutr., 32, 479-489.

Laplace J.P., Darcy B., Pons O., 1983. Digestion dans l'intestin grêle chez le porc. 5 - Importance de la variabilité non contrôlée; modélisation des profils moyens de transit iléo-caeco-colique par régression polynomiale. Ann. Zootech., 32, 201-214.

Laplace J.P., Pons O., Cuber J.C., Kabore C., Villiers P.A., 1981. Effets de la nature de l'amidon (blé ou maïs) et des protéines (poisson ou gluten) sur les facteurs de contrôle et le décours de I'évacuation gastrique d'un régime semi-purifié chez le porc. Applications de l'analyse multidimensionnelle et de la régression polynomiale. Ann. Zootech., 30, 209-248.

Lebart L., Morinead A., Tabard N., 1977. Techniques de la description statistique. Méthodes et logiciels pour l'analyse des grands tableaux. Dunod, Paris.

LeibHOLZ J., 1982. The flow of endogenous nitrogen in the digestive tract of young pigs. Br. J. Nutr., 48, 509-517.

Low A.G., 1979 a. Studies on digestion and absorption in the intestines of growing pigs. 5 - Measurements of the flow of. nitrogen. Br. J. Nutr., 41, 137-146.

Low A.G., 1979 b. Studies on digestion and absorption in the intestines of growing pigs. 6 - Measurements of the flow of amino acids. Br. J. Nutr., 41, 147-156.

Low A.G., 1982. Endogenous nitrogen evaluation from absorption studies. In : LaPlace J.P., Corring T., Rerat A., Physiologie digestive chez le porc, 189-198, Les Colloques de l'I.N.R.A., $\mathrm{n}^{\circ}$ 12, I.N.R.A.-Publ. éd.

Mason V.C., Just A., Bech-Andersen S., 1976. Bacterial activity in the hindgut of pigs. 2 - Its influence on the apparent digestibility of nitrogen and aminoacids. Z. Tierphysiol. Tierernährung. Futtermmitelkde, 36, 310-324.

Pastuszewska B., Duée P.H., Henry Y., Bourdon D., Jung J., 1974. Utilisation de la féverole entière et décortiquée par le porc en croissance : digestibilité et disponibilité des acides aminés. Ann. Zootech, 23, 537-554.

Sauer W.C., Stothers S.C., Parker R.J., 1977. Apparent and true availabilities of amino acids in wheat and milling by-products for growing pigs. Can. J. anim. Sci., 57, $775-784$. 
Souffrant W.B., Köhler R., Gebhardt G., 1982. Détermination de l'azote endogène dans les contenus digestif's par la technique isotopique ("N). In : LAPLace J.P., Corring T.. Rirat A., Physiologie digestive chez le porc, 175-187, Les Colloques de I'I.N.R.A., n" 12, I.N.R.A., publ. Ed.

Wünsche J., Zebrowska T., Hennig U., Kreienbring F., Meini, M., Krawilititzki K., Borgmann E., Volker T., Idzior B., Bock H.D., Buraczewski S., 1979 a. Untersuchungen über die Protein Verdaulichkeit und Aminosaürenresorption in Verschiedenen Abschnitten des Verdauungstraktes beim Schwein. 1 - Tierversuchsmethodik proteingehalte und Aminosaïrenmuster des Dünndarmchymus und des Kotes bei Fütterung unterschiedlicher Rationen. Arch. Tieremähr, 29, 151-164.

Wünsche J., Bock H.D., Hennig U., Kriatendring F., Borgmann E., 1979 b. Untersuchungen über die Proteinverdaulichkeit und Aminosaürenresorption in Verschiedenen Abschnitten des Verdauungstraktes beim Schwein. 2 - Die Protein- und Aminosaiurenbilanz am Ende des Dïnndarms und des gesamten Verdaungstraktes (scheinbare und wahre Protcin- und Aminosaürenverdaulichkeit). Arch. Tieremälhr., 25, 221-234.

ZebrowsKa T., 1973 a. Influence of dietary protein source on the rate of digestion in the small intestine of pigs. I - Amount and composition of digesta. Rocz. Nauk. Roln., $95 \mathrm{~B}, 115-133$.

ZEBROWSKa T., $1973 \mathrm{~b}$. Influence of dietary protein source on the rate of digestion in the small intestine of pigs. II - The rate of protein digestion and aminoacid absorption. Rocz. Nauk. Roln., 95 B, 135-155.

Zebrowska T., Buraczewska L., Buraczewski S., Horszczaruk F., 1975. Digestion and absorption in the small intestine of pigs. I - Digestion and absorption of dry matter and nitrogen. Rocz. Nauk. Roln., 96 B, 79-90.

Zebrowska T., Simon O., Münchmeyier R., Bergner H., 1976. Untersuchungen zur Sezernierung endogener Aminosaüren und den Verdautungstrakt und zur Aminosiürenresorption beim Schwein. Arch. Tierernihr., 26, 69-82.

Zebrowska T., Simon O., Münchmeyer R., Wolf E., Bergner H., Zibrowska H., 1982. Flow of endogenous and exogenous amino acids along the gut of pigs. Arch. Tieremaihr., 32, 431-444.

\section{Annexe - Appendix}

Liste des éléments bibliographiques utilisés à titre d'échantillons de référence dans lanalyse des correspondances (fig. 4-3)

Literature data used as reference sample-points in the analysis of correspondances (fig. 4-3)

1. Fèces d'agneaux axéniques.

Faeces from axenic lambs (COMBE \& PION, 1977).

2. Contenus iléaux de veaux nourris au lait.

Ileal digesta from milk-fed calves (GullLoteAu et al., 1980).

3. Contenus iléaux de porc recevant un régime protéiprive.

Ileal digesta from pigs fed a protein-free diet (WünSCHE et al., 1979 a).

4. Sécrétion pancréatique de porc.

Pig pancreatic juice (CORRING \& JUNG, 1972).

5. Bactéries fécales de porc isolées.

Isolated faecal bacteria from pigs (MASON, JusT \& BECH-ANDERSEN, 1976). 
6. Fèces de porc en régime standard.

Faeces from pigs fed a standard diet (MASON, Just \& BeCh-ANDERSEN, 1976).

7. Fèces de porc en régime protéiprive.

Faeces from pigs fed a protein-free diet (EGGUM, 1973).

8. Fèces de porc en régime protéiprive.

Faeces from pigs fed a protein-free diet (DAMmERs, 1964).

9. Fèces de porc en régime protéiprive.

Faeces from pigs fed a protein-free diet (PASTUSZEWSKA et al., 1974).

10. Muqueuse duodénale de porc.

Duodenal mucosa from pig (RERAT et al., unpublished data).

11. Muqueuse jéjunale de porc.

Jejunal mucosa from pig (RERAT et al., unpublished data).

12. Mucus de porc, partie proximale de l'intestin grêle.

Mucus from the proximal part of the small intestine in the pig (DaRCY, Calmes, unpublished data).

13. Mucus de porc, partie distale de l'intestin grêle.

Mucus from the distal part of the small intestine in the pig (DARCY, CALMES, unpublished data).

14. Mucus de porc, partie médiane de l'intestin grêle.

Mucus from the middle part of the small intestine in the pig (DARCY, CALMES, unpublished data). 